 \\ ETHICAL PRINCIPLES AND STANDARDS AGREEMENT FORM
}

Manuscript ID number: $\underline{657}$

Manuscript Title: Community Based Home Energy Management System

Author(s)-Names, postal addresses and e-mail addresses of all authors:

Muhammad Adnan Aziz, m_adnanaziz@hotmail.com

Dr. Ijaz Mansoor Qureshi, imqureshi@mail.au.edu.pk

Dr. Tanweer Ahmed Cheema, tanweer313@yahoo.com

Akram Rashid, akram@mail.au.edu.pk

\section{Responsibility of Authorship}

In accordance with integrity and ethical behavior in academic works:

a. Only pers ons who have significantly contributed to the research or project and manuscript preparation shall be listed as coauthors.

b. The corresponding author certifies that anyone named as a coauthor has seen the final version of the manuscript and has agreed to its submission for publication. Deceased authors shall be included, with a footnote reporting date of death.

c. The corresponding author accepts responsibility for having properly included all, and only qualified coauthors.

d. This work has not been published, nor is it currently under consideration for publication elsewhere.

I, the corresponding author, confirm all the above statements to be true.

Muhammad Adnan Aziz

Print Name of corresponding author
M/Adrem.

Signature
21-03-16

Date

\section{Plagiarism Issues}

The manuscript must represent original work by the author(s). None of the material should be covered by any copyright; if copyrighted material exceeding approximately 100 words from a journal article or approximately 500 words from a book is used, the author has obtained written permission for its use. Further, this work should not infringe any intellectual property rights/secrecy laws of any person/organization/government/public or private agency, nor should it contain any defamatory matter.

IIUM Press does not bear any responsibility for verifying copyright permissions provided by the author. Any breach of copyright laws will result in retraction of the published article/material as well as reporting to relevant authorities at the authors' institutions.

I, the corresponding author, testify that all of the content, figures (drawings, charts, photographs, etc.) and tables in the manuscript are either my/our original work or work for which permission to re-use has been obtained.

Muhammad Adnan Aziz

Print name of corresponding author

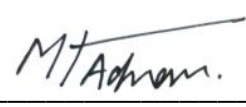

Signature
21-03-16

Date 